\title{
Ética na pesquisa em Educação Física
}

\author{
Research ethics in physical education
}

Júlio César Schmitt Rocha ${ }^{1}$ Tânia R. Bertoldo Benedetti 2

1 Universidade Federal de Santa Catarina. Centro de Desportos. Departamento de Educação Física.

2 Universidade Federal de Santa Catarina. Centro de Desportos. Núcleo de Pesquisa em Cineantropometria e Desempenho Humano. Florianópolis, Brasil.

Recebido em 10/12/08 Revisado em 03/03/09 Aprovado em 17/03/09
Resumo - O objetivo é pensar a ética na pesquisa em Educação Física tendo como pano de fundo a conduta humana individual e coletiva. A questão ética para o ocidente, vem desde Platão com uma incessante busca pelas virtudes para harmonizar o bem pessoal e social e encontra os princípios absolutos de conduta: Autonomia, Beneficência e Justiça. A Educação Física não pode se isentar dos mesmos e das suas inúmeras áreas de desenvolvimento de pesquisas. Além da formação moral que se desenvolve e se solidifica dentro dos grupos sociais cuja característica é a ação de cunho individual, temos que considerar também princípios éticos como os apontados pelo Manifesto Mundial de Educação Física e o da categoria profissional, que balizam o cumprimento do exercício profissional. A pesquisa em Educação Física independente da área de investigação estará sempre num embate entre os princípios éticos institucionais regulamentados pelos diferentes comitês de ética, conselhos, e os valores aceitos pelos pesquisadores. Os comitês buscam preservar a integridade e dignidade dos sujeitos de pesquisas e os pesquisadores desafiam os limites do conhecimento sempre numa fronteira nada cômoda entre o aceito e o não aceito dentro de um determinado contexto de necessidades e visionismo acadêmico.

Palavras-chave: Ética; Educação Física para pesquisadores; Pesquisa.

Abstract - The objective here is to point out ethics in Physical Education research against a backdrop of individual and collective human conduct. Since Plato, the question of ethics in the Western world has been an incessant search for the virtues to harmonize personal and social wellbeing and for the absolute principles of conduct: Autonomy, Beneficence and Justice. Physical Education cannot exempt itself from these and its countless areas of research. In addition to the moral education that develops and solidifies within social groups, the characteristic of which is action on an individual level, we must also consider ethical principles such as those defended by the Physical Education World Manifesto and those that regulate the professional activities of Physical Education professionals. Irrespective of the area investigated, Research in Physical Education will always clash with institutionalized ethical principles enforced by ethics committees, councils and the values accepted by the researchers. Committees strive to preserve the integrity and dignity of the people enrolled on research studies while the researchers challenge the limits of knowledge at an uncomfortable frontier between the acceptable and the unacceptable within a given context of academic vision and needs.

Key words: Ethics; Physical Education; Research Personal. 


\section{INTRODUÇÃO}

Quando pensamos sobre ética, não podemos deixar de considerar que se trata de uma das questões fundamentais e mais antigas da filosofia, onde a preocupação dominante é refletir e explicar racionalmente a conduta humana.

Desde os tempos mais remotos pensadores perceberam sua importância na formação pessoal e no viver em coletividade e buscam entende-la e conceituá-la. Sócrates, Platão e Aristóteles se destacaram na civilização ocidental como precursores deste pensar com maior sistematização. Aristóteles não concebia um mundo sem ética, por entender que ela faz parte do ser humano.

Na origem grega "êthos", ética, quer dizer costume, hábito. É uma característica humana construída histórica e socialmente a partir das relações coletivas dos seres humanos nos ambientes onde vivem. A ética refere-se à moralidade da conduta humana individual e coletiva. Ética é primeiro cuidar-se de si para promover uma existência digna; depois cuidar dos outros, por meio de uma convivência solidária, exercendo a liberdade como um direito fundamental e a responsabilidade como consciência dos atos praticados, conhecendo e reconhecendo os limites da própria liberdade (p. 57)'.

A ética é complexa por ter sempre de enfrentar a ambigüidade e a contradição; por estar exposta a incerteza; por situar-se no limite difuso entre o bem e o mal. E enfatiza que a democracia é antropoética, única a permitir uma relação indivíduosociedade, na qual o cidadão deve sentir-se solidário e responsável ${ }^{3}$.

\section{O SER ÉTICO}

Na sua existência o ser humano se descobre e se realiza enquanto ser moral e ético. Na perspectiva moral, por reconhecer e aceitar para si um conjunto de valores e crenças, cuja repercussão pode ser dimensionada no fazer diário. Na perspectiva ética, ao conciliar esse agir, que é pessoal, com os interesses coletivos em busca da melhor alternativa para todos, minimiza tratamentos desiguais e maximiza benefícios.

É na relação com o outro que surgem os problemas e as indagações morais: Como agir em determinada situação? Como comportar-me perante o outro? Por exemplo: diante da corrupção e das injustiças vigentes, o que fazer?

Vem desde Platão uma incessante busca pelas virtudes (areté) para harmonizar o bem pessoal e o social, mas longe de se pretender princípios absolutos de conduta, alguns deles são mais aceitos e respeitados como balizadores do caminho desejado e esperado para a humanidade. São eles:

- Autonomia: dignidade, respeito à vontade, às crenças e aos valores morais das pessoas;

- Beneficência: maximizar o bem do outro supõe minimizar o mal, atenção aos riscos e benefícios, assegurando-lhe o bem-estar ou diminuindo-lhe o mal-estar;

- Justiça: exigência de eqüidade na distribuição dos bens e benefícios.

Portanto, a ética e seus princípios são utilizados em diferentes situações que exigem uma avaliação, um julgamento entre o que é considerado moralmente bom ou mau, justo ou injusto, certo ou errado. Não podemos achar normal a desigualdade social; precisamos combater o modo de levar vantagem em tudo, a falta de honestidade tão arraigada em nosso meio. Nos setores institucionais, públicos ou privados, estas situações são deploráveis e lamentavelmente, mais uma vez, tão em evidência.

Agimos por força do hábito, dos costumes e das tradições, tendendo a responder conforme a nossa realidade social, política, econômica e cultural. Refletimos pouco sobre o nosso agir e nem temos o hábito de costumeiramente buscarmos os "porquês" de nossas decisões, dos nossos comportamentos, dos valores aqui atribuídos e suas conseqüências. A ética, portanto, tenta contribuir dando subsídios e explicitando reflexões sobre situações práticas, que as pessoas são submetidas diariamente no intuito de preservar a melhor condição humana possível de convívio.

\section{ÉTICA NA PESQUISA}

Ao pensarmos sobre a ciência e as formas diversificadas e constantes do conhecer não podemos desconsiderar as reflexões ligadas à ética. É no fazer diário da ciência que o pesquisador projeta seus valores morais, possibilitando o questionamento de suas intenções e dos meios utilizados. É nesse contexto dialético do pensar que muitos reconhecem a existência da crise da ciência, enquanto outros defendem que sem ela não haveríamos obtido tantas conquistas.

Os paradigmas estão constantemente em xeque. A rapidez, hoje exigida na produção científica submete o pesquisador ainda mais constantemente ao jogo imprevisível entre a "verdade e o erro". É exatamente nesse contexto que a ciência assume 
um papel revolucionário no universo da cultura, colocando o pesquisador entre dois pólos: o da ética do conhecimento e o da ética humana.

$\mathrm{O}$ jogo entre a verdade e o erro se apresenta dialeticamente sob a convivência da certeza/incerteza. E, o que temos como certeza sustenta os avanços. O erro é inseparável da pesquisa como o é a verdade, importa separá-lo da fraude, da utilização maquiada dos resultados esperados.

As pesquisas sofreram um aumento significativo, e, em determinadas situações, esse crescimento pode comprometer a sua qualidade, pois suas publicações passaram, sob forma quantitativa, constituir-se como um forte critério de avaliação nos programas de pós-graduação. Isso não pode constituir desculpa para a fraude e outros abusos. Estes procedimentos representam não só a perda de financiamento e de poder, mas pode pôr em risco todo o controle e a confiabilidade da ciência e particularmente de quem as produz.

A pressão para publicar pode levar a um aligeiramento dos métodos e outras condutas. Esse dilema é o que aflige muitos pesquisadores ou grupos de estudos vinculados aos programas de pós-graduação e linhas de pesquisas.

A exigência de publicações tem consumido os pesquisadores com elevados gastos em busca de espaço nos veículos indexados nacionais e internacionais, além de produzir uma verdadeira fragmentação dos seus trabalhos, por vezes com poucas propostas e muitas constatações, nada contributivo para o avanço interventivo e conceitual. Tal procedimento é mais vantajoso aos seus autores, tanto em termos de reconhecimento entre os pares como avaliativos.

Nas publicações mais recentes, é freqüente exigir uma certa atitude de reciprocidade, no que concerne a autoria dentro do processo de produção científica. São requeridas, sem constrangimento, inclusões de autores que fizeram sugestões de caráter técnico e não participaram efetivamente no seu processo de construção, nem de sua versão final.

Surge o embate entre os valores que cada pesquisador utiliza na sua conduta diária e os impostos atualmente por exigências produtivas, colocando em xeque a autonomia tão almejada por todos. Além desse foro pessoal, é de primordial importância que a comunidade científica se posicione se não para coibir, pelo menos para reduzir tais procedimentos ao discutir seriamente a questão, estabelecendo critérios mais coesos e adequados ao momento por que passamos. Sobre autoria e co-autoria sugerimos o artigo de Petroianu².

As questões éticas levantadas com as devidas adequações também estão presentes no campo interventivo da Educação Física. Por exemplo: atletas, árbitros ou treinadores muitas vezes não medem as conseqüências dos meios empregados para conseguir prestígio e sua ascensão social. As pesquisas invasivas sem respeito à individualidade e integridade do ser humano ampliam as discriminações ligadas às diversas formas de rendimento da área.

Não podemos pensar na Educação Física como uma área única de atuação, pois são muitas, mas os princípios norteadores da autonomia, beneficência e justiça são freqüentes e podem ser utilizados como referência a todas, independentes dos procedimentos e intencionalidades almejados.

Uma preocupação com a ética encontra-se também nos Manifestos Mundiais de Educação Física que objetivaram contribuir, para a ação educativa por meio das atividades físicas, (destaca-se os comentários sobre a ética.) No ano 2000, o manifesto refletiu sobre alguns temas e enfocou a Bioética. Esse documento (23 capítulos) contempla: direito de todos à Educação Física; Educação Física como componente prioritário na educação; perspectiva da Educação Física como educação continuada e compromisso de qualidade; educação para a saúde, lazer e cultura; relação com o turismo e com o esporte; professores como agentes principais da Educação Física; educação contra a discriminação e a exclusão social; Educação Física como instrumento de cultura e paz; responsabilidade com o meio ambiente; papel dos meios de comunicação; e a responsabilidade das autoridades governamentais diante da Educação Física ${ }^{4}$.

Nos manifestos sempre foram enfatizados os treinamentos e a utilização de meios ilícitos na busca pela vitória (doping), evidenciando as preocupações inerentes à nossa profissão.

Da mesma forma, o CONFEF - Conselho Federal de Educação Física, criado em 01 de setembro de 1998, formulou a Resolução 056 (18/08/2003), que dispõe sobre o Código de Ética dos Profissionais de Educação Física. A Resolução caracteriza a Educação Física como atividade de promoção e preservação de saúde para conquistar a qualidade de vida, cujo profissional deve ter competência, honestidade, responsabilidade e atualização técnica, científica e moral, portando-se com respeito à vida, à dignidade, à integridade e aos direitos do indivíduo, levando em consideração os preceitos éticos e bioéticos ${ }^{5}$.

Portanto, as questões de ética (e bioética) já se apresentam nos documentos específicos dos profissionais da Educação Física, nos documentos 
da Comissão Nacional de Ética em Pesquisa (CONEP) e nos Comitês de Ética em Pesquisa com Seres Humanos (CEPs) de diversas instituições e centros pesquisadores ${ }^{6}$.

Independente da área em que esta se desenvolva: educação, esporte, saúde ou tantas outras, a pesquisa em Educação Física deverá sempre cumprir as exigências dos comitês de ética. $O$ primeiro passo é conhecer a Resolução 196, redigir o Termo de Consentimento Livre e Esclarecido - TCLE e explanar claramente ao sujeito de pesquisa o que será realizado.

Infelizmente, a obrigatoriedade de publicação que nos é imposta faz com que as pesquisas não sejam resultados de estudos, reflexões, maturações teóricas, respostas políticas, preocupações sociais, explicações e entendimentos de idéias, mas um aligeiramento do publicar por publicar. A partir disso aparece outro grande vilão da ética na pesquisa: o plágio?

Dentro da pesquisa, talvez o plágio seja o maior e mais freqüente problema ético encontrado atualmente nas produções acadêmicas. Os recursos disponíveis na internet, pelo avanço tecnológico, facilitaram-no sobremaneira. A cópia sem citar a fonte e a apropriação do conhecimento de outros são problemas crescentes encontrados na área da pesquisa em todos os níveis. Começa na infância, quando as crianças copiam seus desenhos, prossegue com alunos da graduação e pós-graduação, e culmina com renomados cientistas que utilizam descobertas de alunos ou de colegas para publicar sem os devidos créditos.

Levantados alguns problemas éticos relacionados ao agir dos pesquisadores e não só do profissional de Educação Física, convém lembrar que as universidades contam com comitês que verificam os projetos de pesquisa, de áreas diferentes ou afins, e os analisa a luz das resoluções e dos princípios éticos existentes.

Tal comitê geralmente é formado por professores da universidade e representantes de alguns setores da comunidade que gratuitamente cedem parte de seu tempo para analisar projetos de pesquisa. Os analistas devem ater-se à Resolução 196 (10/10/1996), do Conselho Nacional de Saúde, que trata da ética na pesquisa envolvendo seres humanos no Brasil, definindo termos e explicitando normas a seguir. Professores, técnicos e alunos que realizam pesquisas com seres humanos devem ler atentamente os itens da resolução e cumpri-los com o máximo de rigor. Sugere-se que alunos de pósgraduação discutam amplamente essa resolução no início do curso. Ações simples como essa poderiam evitar problemas futuros ${ }^{8}$.

Para os pesquisadores, alguns preceitos devem ficar claros. Além da leitura da Resolução 196 do CNS, o Termo de Consentimento Livre e Esclarecido - TCLE deve ter redação clara e apropriada à pesquisa que está sendo realizada, com linguagem acessível a todos os seus participantes, permitindolhes entender o que está sendo dito e pesquisado. Além de assinar o TCLE, os participantes deverão receber esclarecimentos verbais. O TCLE também deverá ser aplicado a crianças ou adolescentes que tenham grau de compreensão compatível ao que será feito. $\mathrm{O}$ mesmo ou outro TCLE deverá ser aplicado aos pais ou responsável.

Outra questão importante é a gravação de fitas, grupos focais e observações participantes em que o pesquisador invade a privacidade do pesquisado, fato que deverá estar esclarecido.

Nas atividades em que se utilizam dados armazenados, como prontuários de pacientes e sangue estocado, deverão solicitar à pessoa o consentimento para utilizar o material, assegurando-lhe o direito de querer ou não participar e ter seus dados expostos em pesquisas, à exceção de banco de dados já organizados.

Sabemos que são questões que dificultam a realização de pesquisas, mas infelizmente o ser humano se distanciou muito do pensamento de Aristóteles que concebia a ética como parte de si. Se fosse assim, não estaríamos escrevendo e discutindo com esta abordagem a presente temática.

Portanto, para facilitar as pesquisas na Educação Física, sugere-se explicar ao grande grupo que será pesquisado ou ao seu responsável o objetivo do trabalho e o que se espera com os resultados, demonstrando a importância da sua participação naquele estudo especificamente para sensibilizálo. Concluído o estudo, seus resultados deverão ser apresentados e discutidos com a pessoa ou o grupo, motivando-o eventualmente a participar de novos estudos.

Nas áreas que exigem processos invasivos, como análise de sangue, urina, outros exames e utilização de fármacos específicos, é necessário que o pesquisado tenha conhecimento de todos os problemas que possam vir a acontecer durante a análise ou os possíveis efeitos colaterais do procedimento. O pesquisador deverá obter aprovação pelo comitê de ética antes de começar a coleta de dados, exigência básica em função do necessário cadastramento no Comitê Nacional de Ética em Pesquisa - CONEP. 
No Brasil foi realizado um estudo com o objetivo de identificar as memórias da licenciatura em Educação Física, no período de 1997 a 2002. Observou que das 89 pesquisas envolvendo seres humanos somente três mencionaram o termo de consentimento, uma o anexou e nenhuma foi submetida a um Comitê de Ética. Apenas uma pesquisa fazia referência à Resolução 196 do CNS. $\mathrm{O}$ autor concluiu que nenhuma delas reuniu todos os requisitos éticos básicos para a sua realização, como: submeter a um Comitê de Ética em Pesquisa, assinar o termo de consentimento livre e esclarecido (TCLE) e outros procedimentos éticos?.

Portanto, só agora nossa área aponta preocupações desta ordem, considerando desde os valores pessoais, que, quer queiramos ou não, estão associados e ou reiterados a todos os procedimentos, momentos de pesquisa e normas legais vigentes institucionais.

\section{CONSIDERAÇÕES FINAIS}

Para finalizar, faltam em nosso meio, não apenas na Educação Física, mas em todas as áreas, a retomada e discussão de valores morais e com eles as virtudes tão necessárias para o viver em coletividade que tanto necessitamos e nem sempre são suficientemente reconhecidas. Autonomia, beneficência e justiça, entre tantas, foram as que destacamos como referencia condutora deste ponto de vista e que não se resumem somente ao entendimento aqui enfatizado.

O constante pensar sobre a materialização das virtudes em qualquer profissão, que só existe invariavelmente para o bem coletivo, e não só pessoal, se faz necessário frente ao crescente e equivocado pensar da vida individualista e de posse que hoje reina. É cômodo este embate? Claro que não. Consensual? Também não. Por isto entendemos virtudes como princípios que não estão estagnados, onde diretrizes são apontadas dentro de posições tão antagônicas, mas necessariamente consensuadas.

As reinterpretações ou busca de novos conhecimentos, se dão pelo enfrentamento cotidiano que passamos, mas em hipótese alguma em detrimento do bem coletivo, ou a favor de grupos seletos. A universalização das ações com base nos princípios pode ser um dos quesitos de sustentabilidade dos procedimentos exploratórios das pesquisas, mesmo que afronte parcialmente alguns dos costumes (mores) vigentes. A capacidade argumentativa apresentando a finalidade pretendida e os possíveis benefícios da investigação são os que podem romper com o estabelecido, oportunizando a permissibilidade da ação.

Se esses princípios (valores) estivessem mais freqüentemente presentes, vivos, cultivados com maior seriedade e discussão, desde o seio familiar, na vida acadêmica e se prolongando pelo existir profissional, não precisariam ser aqui retomados, pois se tornariam efetivamente, como defendem vários estudiosos, constituintes do ser humano, um ser que se complementa e se humaniza pela autonomia, beneficência e justeza.

\section{REFERÊNCIAS BIBLIOGRÁFICAS}

1. Drumond JGF. Ética e Educação Física. p 30-32 Disponível em http://www.confef.org.br/RevistasWeb/n5/ artigo05.pdf [2006 abr 26].

2. Petroianu A. Autoria de um trabalho científico. Rev Assoc Med Bras 2002; 48(1):60-65.

3. Morin E. Os sete saberes necessários à educação do futuro. São Paulo, Cortez; Brasília, DF, 2001.

4. FIEP. Manifesto Mundial de Educação Física. 2000. Disponível em: http://www.saudeemmovimento.com. br/conteudos/conteudo_exibe1.asp?cod_noticia $=173$ [2006 mai].

5. CONFEF. Regulamentação da Educação Física no Brasil. Disponível em http://www.confef.org.br/extra/ conteudo/default.asp?id=16. [2007 jun].

6. UFSC. Comitê de ética em pesquisa com seres humanos. Disponível em: http://www.cep.ufsc.br/index2. php?pg=home.php. [2006 abr].

7. Evangelista O. Publicar ou Morrer. In: Bianchetti L, Machado AMN. Oranizadores. A Bússola do Escrever: desafios e estratégias na orientação de teses e dissertações. Florianópolis: Editora UFSC, 2002. p. 297-300,

8. Brasil. Manual operacional para comitês de ética em pesquisa. Ministério da Saúde/Conselho Nacional de Saúde. Brasília, DF. 2002.

9. Botelho RG. Análisis de los aspectos éticos de las memorias de maestría en educación física que involucran seres humanos de una institución de enseñaza superior - 1997 a 2002. Lecturas: Educación Física y Deportes 2006; 10(93).

\section{Endereço para correspondência}

Tânia Bertoldo Benedetti

Departamento de Educação Física - Centro de

Desportos, UFSC

Campus Universitário, Trindade

Caixa Postal $\mathrm{n}^{\circ} 476$

CEP: 88.040-900 - Florianópolis, SC. Brasil

E-mail: benedetti@cds.ufsc.br 